\title{
DOCUMENTACIÓN MUNICIPAL. EL PROCEDIMIENTO DE QUINTAR MOZOS EN LOS SIGLOS XVIII ${ }^{1}$ Y XIX ${ }^{2}$, LEGISLACIÓN
}

\author{
MUNICIPAL DOCUMENTS (SPAIN). PROCEDURE MILITARY IN \\ REPLACEMENTS OF EIGHTEENTH AND NINETEENTH CENTURIES
}

\author{
Antonia CRiado LÁzaro \\ Archivera Municipal de Torrelodones (Madrid)
}

\begin{abstract}
Resumen: Los expedientes de Quintas llenan las estanterías de los archivos municipales españoles, si bien, su estudio hasta ahora ha sido escaso, marginal o centrado en la segunda mitad del siglo $\mathrm{XX}^{3}$. En el presente estudio se aportan los fundamentos legislativos del procedimiento de "Quintar" en los reemplazos militares de los siglos XVIII y XIX y se describen algunos expedientes de esta serie archivística, pertenecientes al Patrimonio Documental Histórico de los Ayuntamientos de Griñón y Torrelodones.

Palabras clave: Archivos. Archivos municipales españoles.Documentos de archivo. Griñón (Madrid). Quintas. Quintas y Milicias. Reemplazos militares. Series documentales históricas. Servicio Militar. Torrelodones (Madrid).
\end{abstract}

\begin{abstract}
Quintas records fill the shelves of Spanish municipal archives; while so far the study has been limited, or focused merginal in the second half of the twentieh century. In the present study provided the legislative basis of the procedure for Quintas in the military replacements eighteenth and nineteenth centuries and descrives some archival records belonging to these series Historical Documentary Heritage of the councils of Griñón and Torrelodones.
\end{abstract}

Keywords: Griñón (Madrid). Military replacements. Military service. Quintas. Quintas y Milicias. Records. Series historical documentary. Spanish municipal archives. Torrelodones (Madrid).

La Serie archivística de la Administración Local "Quintas y Milicias", que hunde sus raíces en la Edad Media, responde a la función delegada por la Administración Real en los municipios para formar las milicias concejiles, ante la necesidad de completar las huestes señoriales o reales. En base a los "repartimientos de sangre" o cupos establecidos, generalmente proporcionales a su población y con exención de cargos, funcionarios y otros privilegiados, los alcaldes realizaban los reclutamientos de los jóvenes que se pondrían bajo el mando militar de un capitán.

Alfonso X ya mencionaba esta obligación de asistencia en los llamamientos de todos sus vasallos, so pena pecuniaria:

\footnotetext{
1 Estudio realizado sobre el Fondo Documental del Archivo Municipal de Griñón-Madrid, (AMG).

2 Estudio realizado sobre el Fondo Documental del Archivo Municipal de Torrelodones-Madrid, (AHMT).

3 GARCÍA RUIPÉREZ, Mariano. Tipología Documental Municipal [Toledo], 2002, p.121.
} 
Quando el rey fiziere pregonar su hueste, quier contra moros quier contra otros cualesquier, el conçeio o los otros cualesquier que deven hyr sin soldada a ella, si non fuere al plazo que les fue mandado así como deven, pechen la fonsadera como el rey mandare. Et esa misma pena ayan los que se vinieren sin mandado ante que devíen ${ }^{4}$.

En la Baja Edad Media ${ }^{5}$, durante el reinado de Juan II, en sus Cortes de Zamora de 1432 en la petición 49, especifica la obligación de sus vasallos a servir personalmente en las guerras, sin excusarse sino por enfermedad, vejez u otra ocupación legítima. ${ }^{6}$, pero excusa en las peticiones 23 y 24 del servicio militar a aquellas personas por ejercer ciertos oficios considerados imprescindibles para el funcionamiento de la Administración. Lo contenido en estas últimas peticiones son recordatorio de lo ya había quedado establecido en las Cortes de 1429 en Burgos, peticiones 31 y $33 \mathrm{y}$, salvo las excepciones lógicas de extinción o nuevos oficios que conlleva el paso del tiempo, se repetirán en posteriores llamamientos y reemplazos hasta el siglo XIX:

Ordenamos que en los llamamientos que Nos hiciéremos para las guerras, sean excusados de ir a la guerra los Alcaldes, os Alguaciles, Regidores, Jurados, Sesmeros, Fieles, Montaraces, Mayordomos, Procuradores, Abogados, Escribanos del Número, Físicos, Cirujanos, Maestros de gramática y escribanos que muestran a los mozos a leer y escribir de las ciudades y villas de nuestros Reynos, salvo cuando tuviésemos necesidad dellos... y otro sí sean excusados e ir a la guerra los arrendadores recaudadores, cogedores y empadronadores y pesquisidores de nuestras Rentas ${ }^{7}$.

Los sucesivos reyes seguirán legislando prolíficamente sobre este asunto tan importante sin dejar de recoger toda la legislación anterior, así, durante el reinado de los Reyes Católicos en la Copilación de las leyes del reino que mandaron componer en 1484 a Montalvo, en su Lib. IV, Tít. III, De los vasallos del rey y en el Tít. IV, De los escusados y esentos, entre otras leyes.

Carlos I y su madre Juana I, por su parte, tienen que dar leyes para evitar las quejas de los abusos de la soldadesca en los territorios y poblaciones por la que pasaba, en las Cortes de Valladolid de 1523, pet. 44, Prohibición a las gentes de guerra de comer a costa de los pueblos; sobre que el Consejo de las providencias necesarias [para ello], que reproducirán como recordatorio en las de Toledo de 1525, pet. 41, de Madrid en 1528, pet. 44 y de Valladolid en 1537, pet. 94, ${ }^{8}$.

Llegamos al siglo XVIII y Felipe V en 1704 manda que se reclute un hombre de cada casa, utilizando el término "quintar" como equivalente de repartir, en lo que en nota marginal explicando sucintamente el contenido de la carta dice:

El alcalde, uno por cien para la recluta de quintos ${ }^{9}$.

4 Alfonso X, Fuero Real, Lib. IV, Tit. 19, Ley. 3.

5 Sobre el servicio militar en la Baja Edad Media, registro de peones, actas de alardes, padrones de mozos y actas de sorteos, se hace referencia en CAYETANO MARTÍN, Carmen [et al]. Los archivos de la Administración Local, Toledo, 1994, ps.61-62.

6 Novísima Recopilación de las leyes de España. Lib. VI, Tít. VI, Ley I

7 Novísima Recopilación de las leyes de España. Lib. VI, Tít. VI, Ley II.

8 Novísima Recopilación de las leyes de España. Lib. VI, Tít. VI, Ley III.

9 Orden Real dada en Madrid en 6 de septiembre de 1704. 
Un año después, pero ya en 1705 el cupo se ajusta la tradicional saca de un joven por cada cinco listados:

Que de los comprendidos en la lista se saque por suerte de cinco uno y se execute inviolablemente. Que hecho el sorteo en la dicha forma se conduzcan las personas a quien tocare a la Cabeça de Partido más cercana y de allí a la Plaça de Armas que por nuestra Real Persona se señalare. Que sea de la obligación de cada una de essas dichas ciudades, villas y lugares mantener vivos los soldados que le tocaren, subrogando otro en lugar de el muerto, huido o prisionero de aquellos que se comprenhendieren en la primera lista, volviéndose a sortear en la misma forma ${ }^{10}$.

En la exposición de esta misma Provisión ya había quedado justificada la utilización del uno por cinco, en base a las tradiciones nacionales españolas, corrigiendo órdenes anteriores y que certifica su práctica ancestral:

... sabed que siendo preciso reclutar los cuerpos de españoles que sirven en aquellas fronteras para su defensa y no bastando las levas mandadas hazer, se ha tenido por medio más conveniente y proporcionado el de quintar, por las reglas y en la forma antes de ahora practicadas en estos nuestros reynos ${ }^{11}$.

En el Pardo, en 1734, con la Real Ordenanza de 31 de enero, se establece lo que podría entenderse como el primer ejército permanente, es decir, una fuerza regular, en esta ocasión, de treinta y tres regimientos cuyos soldados serán sorteados en cada pueblo atendiendo al cupo proporcional asignado a su población:

Teniendo por indispensable providencia la de poner en disposición de servicio regular y útil para la defensa y mayor seguridad de mis reynos algunos regimientos de Milicias repartidos con proporción a los vecindarios... las compañías se formarán en los lugares de cada partido... siempre que muriere o enfermare o por algún motivo se ausentare alguno de los soldados de las Compañías, nombrarán luego los Alcaldes otro con aprobación del Capitán... ${ }^{12}$

Del seguimiento de este procedimiento contamos con un primer ejemplo de 1742. Se trata del "Repartimiento y sorteo de mozos quintos" de la Mancomunidad formada por Griñón, Cubas, Serranillos, Casarrubuelos, Boadilla y Aravaca, para "sacar" dos soldados con el fin de servir en el Ejército durante tres años y que se conserva y custodia en el Archivo Municipal de Griñón ${ }^{13}$. Por reparto del cupo provincial les había tocado sacar dos soldados mancomunadamente.

El expediente se compone, como en general todos los expedientes de Quintas, de actas, certificados, autos y diligencias de Notificación y Cumplimiento de la orden, Rectificación del Alistamiento, Entrega de los Soldados, Relaciones de Mozos inscritos y Sorteos de Quintos.

\footnotetext{
10 Real Provisión dada en Madrid a 7 de marzo de 1705.

11 Real Provisión dada en Madrid a 7 de marzo de 1705

2 Novísima Recopilación de las leyes de España. Lib. VI, Tít. VI, Ley IV.

13 AMG. Expedientes Generales de Reemplazo. DH 57/2.
} 
Se da comienzo con un acta titulada Griñón y sus pueblos mancomundados para dos soldados, que hace referencia a la Real Instrucción ${ }^{14}$ impresa remitida por el Corregidor y Superintendente de Rentas Reales de la Villa de Madrid. En presencia de los individuos (justicias, escribano y síndico ${ }^{15}$ ), cirujano ${ }^{16}$ del Ayuntamiento, del cura párroco ${ }^{17}$, de los mozos o sus tutores y demás vecinos, el veinticinco de enero del citado año, convocados todos a la voz de campana tañida, según costumbre, siendo como a las tres oras de la $\operatorname{tarde}^{18}$, tiene lugar el "encantarado"19, sacando ellos mismos su suerte o sus familiares en su nombre de estar ausentes.

Es frecuente que se tuvieran que realizar dos sorteos ante la no presencia, fuga o no haber "dado la talla" los llamados a quintar. En nuestro ejemplo, hubo que ir a buscar a su casa al soldado que no se presentó en el Ayuntamiento para, posteriormente, conducirle a la cárcel $^{20}$, de donde partiría al día siguiente para Madrid con el otro mozo sorteado.

En el mismo expediente se conservan los certificados del resto de los pueblos que componen la Mancomunidad $^{21}$ con las relaciones de los mozos que cumplen los requisitos, según la normativa vigente (solteros, sin familiares que dependan de él, de dieciocho a cuarenta años, físicamente "válido", no exento por razones de oficio...). Entrarían en sorteo, también, los inquietos y holgazanes mozos solteros que no atiendan a las obligaciones de sus casas y familias, prendiéndolos y asegurándolos antes del día del sorteo ${ }^{22}$, haciéndose evidente la desconfianza gubernamental sobre la fidelidad a la patria de los mozos quintados.

En los certificados citados, el cura párroco da fe de que en el libro corriente ${ }^{23}$ de bautizados en dicha parroquia...se hallan los mozos de diez y ocho años hasta los cuarenta cumplidos que se han bautizado en dicha iglesia ${ }^{24}$.

14 AMG. Expedientes Generales de Reemplazo, DH 57/2.1. Es muy frecuente encontrar en los archivos municipales las instrucciones, órdenes, decretos. comunicaciones, etc., de la Superioridad que regían los procedimientos formando parte del expediente, de la misma manera que posteriormente se conservarían las gacetas y boletines oficiales del Estado, de las provincias y comunidades autónomas hasta su difusión en web que evitan acumular papel. Las normas legales rigen los procedimientos y el archivarla junto a su expediente, es una eficaz manera para los funcionarios de asegurarse su estricto cumplimiento. La instrucción llegaba "por vereda" en forma de circular nominativa al Ayuntamiento, cuyo acuse de recibo deberían de firmar.

15 Los justicias y alcaldes dirigen el procedimiento y se encargarán de llevar personalmente a los mozos a la cárcel de Corte; el escribano toma nota de todo lo que sucede y da fe y el Síndico Personero actuaría como defensor de los quintos. Más adelante, como veremos, se nombrará expresamente un Defensor del Soldado, sin que intervenga el Síndico personero.

16 El cirujano examina física y mentalmente a los quintos

17 Personaje indispensable en los procedimientos de "quintar" por dar fe y aportar los libros de nacimiento, como único padrón fiable, incluso, cuando ya en el siglo XIX los ayuntamientos cuenten con sus propios padrones, se seguirán cotejando con los parroquiales.

18 AMG. Expedientes Generales de Reemplazo, DH 57/1.1.

19 Procedimiento por el que se introducían cédulas con los nombres en un cántaro y en blanco o con la suerte de soldado en otro. Posteriormente las cédulas se meterán en bolas huecas y el cántaro puede sustituirse por bolsas o globos

20 La cárcel era el lugar donde permanecían custodiados todos los mozos desde que eran sorteados hasta su entrega en la Caja Militar de Madrid.

21 Es lógico suponer que cada población cuenta o tuvo que contar con un traslado de todo el expediente, no solamente de los documentos generados en su Ayuntamiento.

22 Real despacho de cinco de diciembre de 1741 y trasladada a los pueblos de la Mancomunidad en enero de 1742.

23 Recordemos que es frecuente encontrar en los archivos parroquiales otros libros, también de bautizados como el llamado "Libro prohibido de niños" en el que se inscribían los expósitos.

24 AMG. Expedientes Generales de Reemplazo, DH 57/1.12. 
La entrega en Madrid cuenta con su "Certificado de Inspección y Reconocimiento" del comandante de la Cárzel Real de esta villa [Madrid] de los mozos conducidos presos ${ }^{25}$ por tropa militar por el lugar de Griñón y sus agregados.
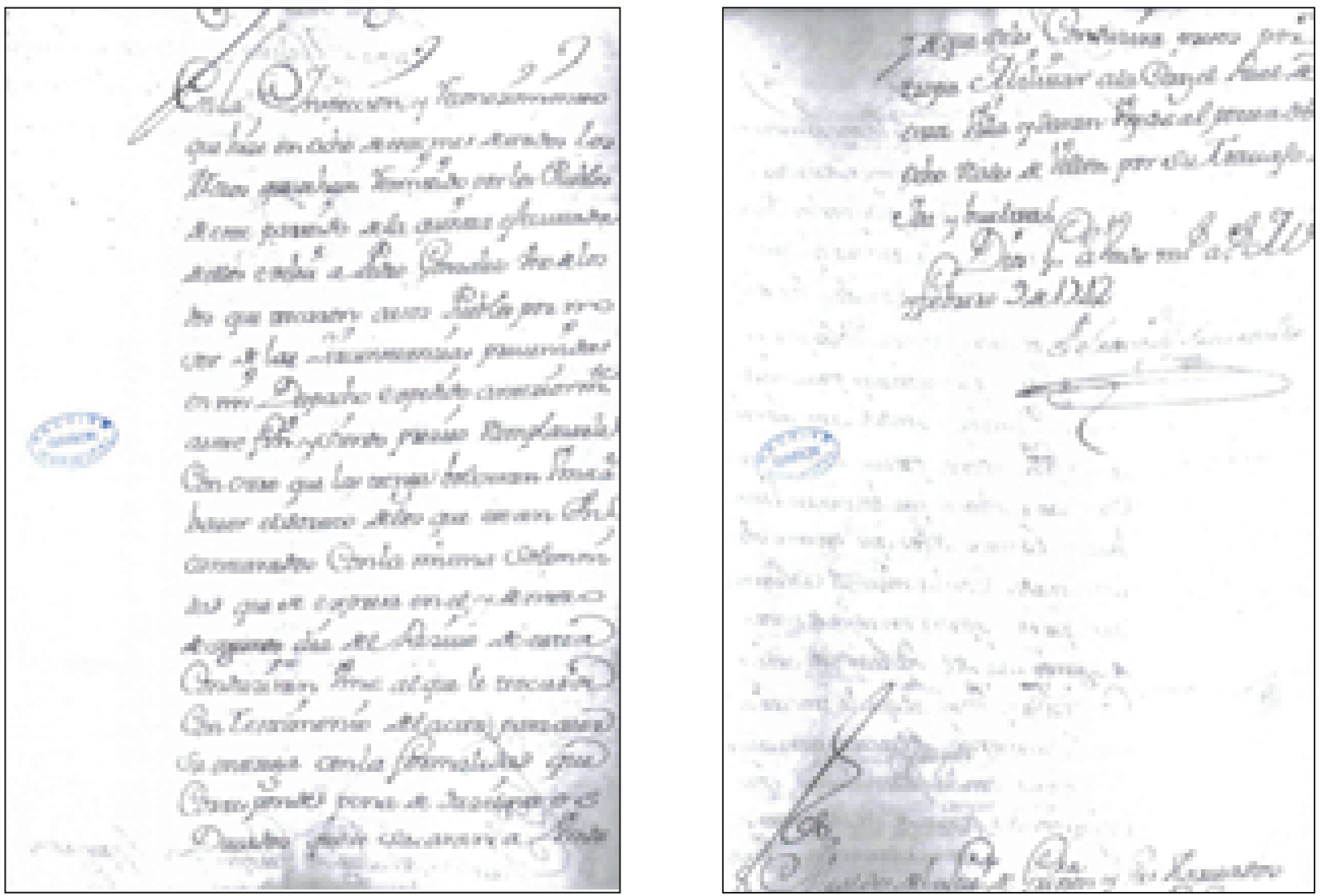

Comprende también el expediente el documento de "Acuerdo entre los pueblos" para pagar los gastos de mantenimiento en la cárcel de Griñón de los mozos "acantarados" hasta ser remitidos a Madrid y aprobados por el Corregidor de Villa ${ }^{26}$.

Para 1762, Carlos III da la Ordenanza de su majestad para la quinta de ocho mil hombres que debe hacerse con destino al reemplazo de los regimientos de infantería española ${ }^{27}$ para completar mi exército, por no haver bastado para lograr este fin el número que produxo la última Quinta. Se trata de una ordenanza innovadora en cuánto a que se toman medidas para realizar padrones de mozos más ajustados a la realidad, así como modificar las injustas exenciones que se venían aplicando tradicionalmente.

25 Esta conducción de presos, se están rememorando las “cuerdas de presos” que consistían filas de reos esposados con cuerdas o cadenas y, a la vez, sujetos a una cuerda común.

26 AHM_Griñón. Expedientes Generales de Reemplazo, DH 57/2.8.

27 Ordenanza de su majestad para la quinta de ocho mil hombre que debe hacerse con destino al reemplazo de los regimientos de infantería española, Madrid, 1762. 
El motivo real es la necesidad de soldados en los ejércitos españoles en este momento, producido por la entrada de España en la Guerra de los Siete años (el año anterior se había firmado el "Tercer Pacto de Familia" con la Corona Francesa), después de que Gran Bretaña invadiera Honduras y Québec. En esta ocasión serán ocho mil soldados de entre diecisiete y cuarenta y dos años y para cinco años. Estas condiciones amplían tanto el margen de edad de los soldados, como el período a servir en el Ejército.

De esta época contamos con otro expediente ejemplo que incluye esta instrucción que, como es habitual, viene acompañada en comunicación personal impresa, remitida por vereda y con acuse de recibo del Corregidor de Madrid e Intendente General de la provincia, nominativa a cada Ayuntamiento y consignando el cupo establecido ${ }^{28}$.
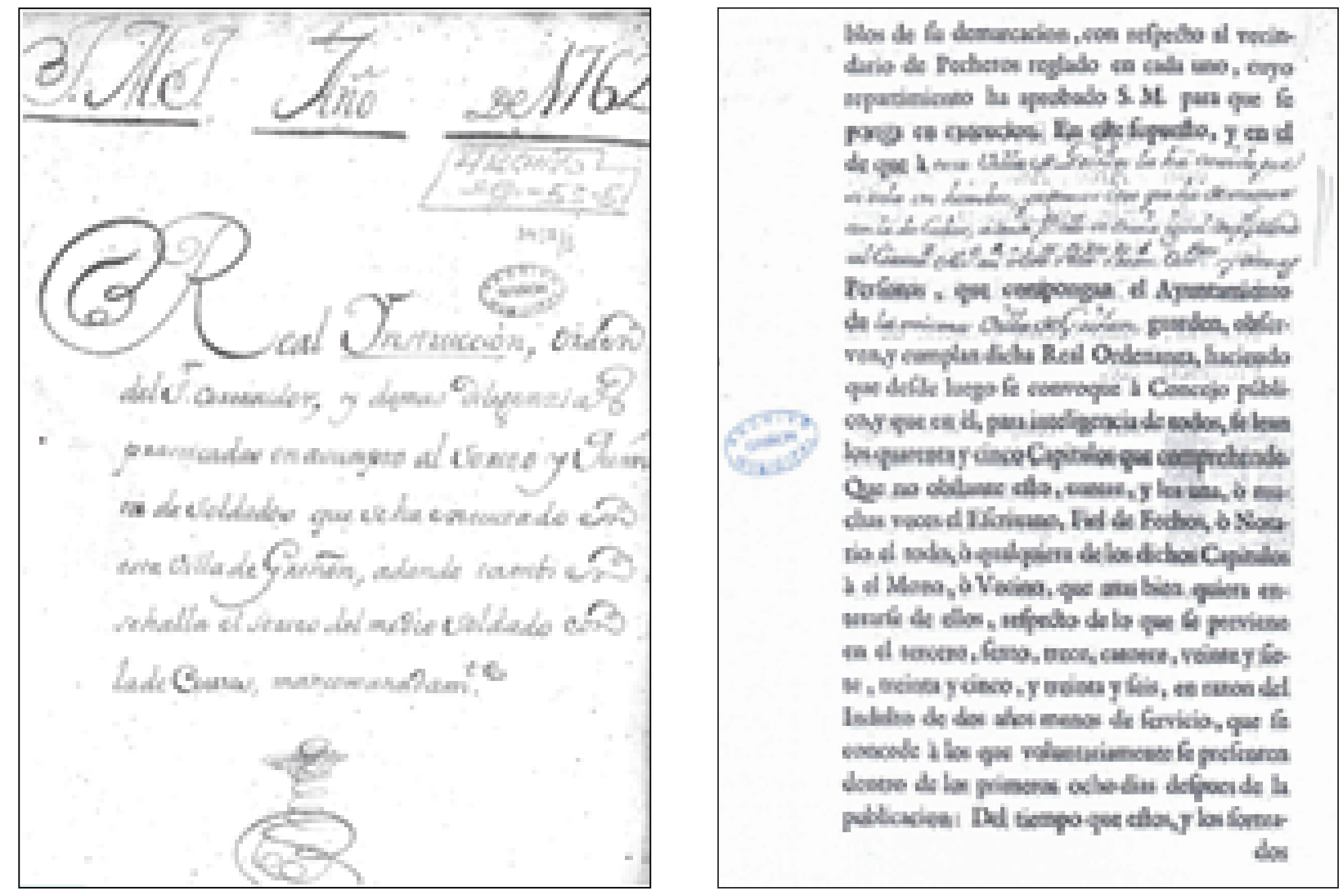

La citada Ordenanza de 1762, en su justificación y exposición de motivos inicial hace toda una "declaración de principios" a favor de los vecinos, resultando innovador, como queda dicho, el "mea culpa" del rey y su Administración al reconocer lo injusto y parcial para los habitantes del reino las exenciones practicadas hasta ese momento y su intención de rectificar:

... y habiendo reconocido con el mayor dolor que en su ejecución han sufrido mucho mis pueblos, no tanto por la extracción de sus vecinos y habitantes como por el mal

\footnotetext{
28 AHM Griñon. Expedientes Generales de Remplazo, DH 57/2
} 
método y desigualdad en el repartimiento por la falta de vigilancia y desvelo de algunos de los Intendentes, corregidores y oficiales militares, comisionados para ella, por la parcialidad y favor de las justicias por las colusiones de escribanos, médicos y cirujanos y últimamente por la protección que han prestado algunos prelados $\mathrm{y}$ eclesiásticos seculares y regulares a fin de eximir de la Quinta a no poco número de mozos hábiles para las armas...

De la misma forma, también es importante y novedoso el empeño que se pone en este momento de realizar un padrón de mozos lo más fiel posible al número real y, además, con proporción a su vecindario ${ }^{29}$.

Además del acta de "Notificación" y "Cumplimiento" de la orden del corregidor de cada pueblo, el expediente contiene otros documentos como son los "Requerimientos" a los padres de mozos en edad de quintar para que les tuvieran promptos siempre que se les mandase comparecer para la medida de sus estaturas y reconocimiento de sus calidades y zircunstanzias; las "Diligencias" de las propias medidas de estaturas:

... para lo qual, haviéndose traído una marca que dieron en el Cuartel del Vicak, sito en la Puerta del Sol de la villa de Madrid y fixándose en la pared del referido Ayuntamiento en un listón de madera para formalizar más exactamente y sin agravio alguno de las partes este acto, se executó a toda satisfacción de los nominados mozos y sus respectivos padres y que se hallaron de los cinco pies cumplidos que previene la ordenanza.

A continuación, autos de "Rectificación" de Quintados.

También, "Certificados Médicos" y el acta del "Sorteo" en la plaza pública, con todo el Ayuntamiento presente, así como el cura párroco con sus libros y los vecinos, para seguir el tradicional sistema de "Encantaramiento" y extracción de las cédulas, en esta ocasión por un niño de corta edad.

Para, finalmente, incorporar la "Fe" del escribano de haber remitido a Madrid a dos soldados sorteados, remisión que, como en veces anteriores, tenía lugar de noche, a las tres de la madrugada y custodiados por alcaldes y regidores para ser entregados en la Real Casa del Ayuntamiento de Madrid $^{30}$.

En su retiro de Aranjuez en 1766, el rey, dio el Reglamento para el ejército de las Milicias que perfeccionará la elaboración de Quintas, padrón y sorteos de mozos aptos. Además, entre otros asuntos, se aumentan los regimientos de treinta y tres a cuarenta y dos y se fijan las excepciones de los pueblos que avituallan a la Corte:

Sólo quedarán exceptuados de ella los pueblos de las diez leguas de Madrid, por el extraordinario servicio de cuarteles y otras gavelas con que contribuyen a mi Corte ... ${ }^{31}$

\footnotetext{
29 Ordenanza citada, p. 4. Novísima Recopilación de las leyes de España. Lib. VI, Tít. VI, Ley IV.

30 La conducción de los quintos a Madrid se realizaba a pié y, por precaución ante las posibles fugas de los soldados, como vemos, bien custodiados.

31 Novísima Recopilación de las leyes de España. Lib. VI, Tít. VI, Ley V.
} 
Esta excepción de diez leguas es el motivo por el que Archivos como el de Madrid o Torrelodones no tienen en sus Archivos expedientes de Quintas hasta bien entrado el siglo XIX, en concreto 1821, ya con el Trienio Liberal. Efectivamente, en el caso del pueblo serrano mencionado, desde la construcción de El Escorial, también era frecuente que sus posadas y tabernas fueran parada y fonda de numerosos personajes de la Corte, soldadesca y hasta del propio rey, que dejaban buenas ganancias pero que, también, causaban ocasionalmente algunos gastos.

Por otra parte, solamente un año más tarde, en 1767 en Aranjuez, el rey por Real Declaración concretará las clases de personas que quedan exentas del servicio en Milicias que, en esencia, son las mismas desde la Edad Media, como anticipábamos más arriba, pero muy ampliado el capítulo de los privilegiados, a pesar de las buenas intenciones ya comentadas de la ordenanza de 1762:

... serán exentos todos los nobles e hijosdalgo... de los ministros y dependencias de la Inquisición y de Cruzada serán exentos los que deban serlo de alojamiento y casas concejiles.. los dependientes de mis Tribunales de Justicia.. los Procuradores el Número y Notarios de Audiencia e los Juzgados de Obispo y Provisor... el Escribano de Cabildo y los de Número, pero no sus hijos... los que componen la Administración de Rentas... los Oficiales de la casa de la Moneda... Un Mayordomo de Comunidad eclesiástica... el Mayordomo de la ciudad o villa... el Síndico de San Francisco... los Sacristanes ... los labradores de dos arados de mulas... los Maestros de escuela y Gramática y uno de sus hijos... los Médicos aprobado... los Cirujanos aprobados... Un Sangrador aprobado... Los albéitares y herradores examinados y un hijo... Los boticarios y un hijo... Los empleados de Correos y postas con título y salario... Los que tuvieren padre, hijo o hermano en actual servicio de Milicias o en el Exército por haber sido quintado.... Los que hayan servido sin intermisión en el Exército o Milicias... a todas las personas ilustres se les han de exceptuar del alistamiento de Milicias aquellos criados de estimación... los cocheros que sirvan con librea... los mercaderes de lonja o tienda de caudal considerable en el comercio y los mancebos indispensables... los estudiantes matriculados...los ordenados de menores y Primera Tonsura... ${ }^{32}$

En la siguiente Ley, de la misma Real Declaración, se explica la manera de dividir los vecindarios para los sorteos de Milicias:

Con el fin de que el servicio de Milicias, en quanto fuere dable, sea menos gravoso a mis pueblos y vasallos, incluyendo en los sorteos a los menos menesterosos para el cuidado de sus bienes y familias, mando que los vecindarios para el alistamiento se dividan en cinco clases.

Consisten las divisiones una clasificación entre solteros, casados, viudos, con hijos, sin hijos $\mathrm{y}$, en esta ocasión, se excluye a aquél que se haya tomado por vagabundo o mal entretenido, con nota de delito feo, ni al que tenga de oficio indecoroso o extracción infame, como mulato, gitano, carnicero, pregonero o verdugo.

\footnotetext{
32 Novísima Recopilación de las leyes de España. Lib. VI, Tít. VI, Ley VII.
} 
Siguiendo con la misma Declaración Real, en la ley IX, se vuelve a fijar la manera de ejecutar el sorteo, con aclaraciones y dudas sobre el proceder del secretario, cura, repartimientos, rectificaciones, entrega de los soldados, lugar de realización del sorteo, etc. Reproducimos la descripción del "encantaramiento" y extracción de la suerte del quinto de esta instrucción por tratarse de una descripción muy completa que da constancia del cumplimiento de las reales provisiones de 1704 y 1705 mencionadas más arriba, no habiendo cambiado sustancialmente en los dos siglos estudiados ${ }^{33}$ :

40. Con anticipación al acto del sorteo ha de tener prevenida la Justicia una porción de bolillas de madera ovaladas, que sean todas iguales y capaces de recibir cada una en su centro (que ha de estar barrenada a la larga) una cédula enrollada de pergamino o papel que debe introducirse en el hueco.

41. ... en unas cédulas estarán escritos con toda claridad los nombres de los individuos que deben sortear... quedando las demás en blanco.

42. ... habrá en medio de la sala Capitular una mesa con dos bolsas o cántaros: la Justicia hará manifestar a los concurrentes tanto las cédulas como todo lo demás para el que quisiere de los interesados o de los que asistan de oficio al sorteo reconozcan si hay o no algún fraude. Después se enrollarán igualmente todas las cédulas donde están los nombres de los que han e entrar a sortear y se introducirán en las bolillas de modo que no puedan caerse ni sobresalgan por los extremos y todas se pasarán a uno de los cántaros o bolsas y lo mismo se executará con las otras cédulas en blanco y donde esta escrito el nombre del soldado; y en estando cada una en su correspondiente bola con las mismas precauciones se pondrá en la otra bolsa o cántaro y tanto las de una parte como las de otra se moverán a fin de que se mezclen e incorporen unas entre otras y se evite todo rezelo o sospecha de ilegalidad en el modo de tirar la suerte.

43. Estarán prevenidos y presentes en la misma sala dos niños de seis a ocho años con destino a sacar las bolas el uno de la una bolsa o cántaro y el otro de la otra y tendrá cada uno e los dichos niños un palillo a propósito para que introduciéndole por el un lado de la bola salga la cédula por el otro.

44. Luego que se halle todo pronto se mandará a los niños destinados a las bolsas o cántaros saquen cada uno del suyo una bola y que con el palillo echen fuera la cédula que contiene, la que desdoblarán los mismos niños y leerán en alta voz, si saben, empezando el que sacó la bola de la bolsa o cántaro donde están los nombres de los individuos y después el otro y en caso de no saber leer, irán entregando sus respectivas cédulas para que lo execute el cura párroco y en falta de éste y su teniente, el síndico procurador. El escribano estará presente a todo, pues que ha e dar su testimonio. Y de este modo se proseguirá hasta haber concluido con todas las bolas de uno y otro cántaro o bolsas y el mismo escribano irá notando inmediatamente, tanto los nombres de los que vayan saliendo, como si la otra cédula que le correspondió fue en blanco o con el nombre del soldado, continuando el extraer las bolas de los cántaros o bolsas por el mismo orden hasta que hayan salido quantas se encantararon.

45. Concluidas las bolas se volcarán los cántaros y siendo bolsas se volverán lo de adentro a fuera para que todos vean no haber quedado ninguna y que el sorteo se ha ejecutado fiel y legalmente.

\footnotetext{
33 Novísima Recopilación de las leyes de España. Lib. VI, Tít. VI, Ley IX, núm. 40-45.
} 
Posteriormente, se fijará el sorteo con dos tipos de bolas, unas con la cédula que lleva escrito el nombre del soldado y otras vacías negras o blancas, en igual número, las primeras, que el cupo de soldados y hasta completar el número de sorteados las segundas.

En 1773 el rey da una interesante cédula dirigida a los secretarios y escribanos que intervienen en los procedimientos de reclutamientos y quintado de soldados. Se ordena que, por regla general, que sean los escribanos del Ayuntamiento los que actúen en todos los negocios relativos al sorteo y que las órdenes ${ }^{34}$, papeles y documentos tocantes a reemplazo se deben guardary archivar con los del Ayuntamiento, como fechos que son de él, por cuyo motivo es consiguiente se deliberen ante su propio Escribano de Ayuntamiento ${ }^{35}$.

Durante todo el siglo XIX España tuvo gran necesidad de realizar continuos reclutamientos y levas militares, dados los tiempos tan convulsos que provocaron un estado de guerra casi permanente por sus asonadas, pronunciamientos militares, guerras civiles e internacionales. No obstante, ningún gobierno encontró la tranquilidad suficiente para promulgar otro reglamento, de modo que las leyes de reclutamiento no sufrieron cambios importantes desde la Guerra de Independencia hasta la Restauración ${ }^{36}$.

Poco antes, el 27 de octubre de 1800, Carlos IV había promulgado una Ordenanza para el anual reemplazo del Exército, con la que se vuelven a fijar, entre otros asuntos:

El modo de formar y rectificar el padrón del vecindario de los pueblos para el servicio del reemplazo del Exército; su lectura y otras formalidades en los Ayuntamiento; el modo de hacer las Justicias el alistamiento de todos los mozos y de las licencias que han de dar a los que pasen a otros pueblos; modo de rectificarlo en el Ayuntamiento y de medir a los mozos para el desecho de los inútiles; las formalidades que han de observarse en el acto del sorteo para el juicio de excepciones de los mozos alistados; los exentos del sorteo para el servicio del reemplazo; el encantaramiento de las bolas, sorteo y personas que han de asistir a él; la prohibición de poner substituto los sorteados; modo de proceder contra los prófugos del sorteo; su pena y de los que les auxiliaren; la filiación, asistencia y conducción de los sorteados y de las obligaciones del Oficial aprobante; el destino de los quintos de una provincia o partido a un mismo cuerpo y su conducción a los Regimientos ${ }^{37}$.

El Reglamento de 1802, seguirá básicamente otro dado en 1767 ante la extrema necesidad de aumentar tan fuertemente el Exército ${ }^{38}$. Había que cubrir, de nuevo, las bajas de guerra, en esta ocasión, cuando Godoy declaró la guerra a Portugal como aliada de Gran Bretaña, un compromiso ineludible desde la firma el año anterior del Convenio de Aranjuez con Napoleón en 1801.

34 Gracias a esta orden es posible encontrar en los Ayuntamientos estos expedientes y no en otras dependencias de la Administración Territorial o Estatal, además con el mandato expreso de archivar las órdenes con sus expedientes, también se ha podido conservar la legislación en su impreso original. En la actualidad, es suficiente con la referencia legal en el documento y si hubiere boletines oficiales impresos, no se conservan por considerarse apoyo informativo y poder consultarlos en centros bibliotecarios y documentales.

35 Novísima Recopilación de las leyes de España. Lib. VI, Tít. VI, Ley XI

36 FEIJÓO GÓMEZ, Albino. Quintas y Protesta Social en el Siglo XIX, Madrid, 1996, p.36.

37 Novísima Recopilación de las leyes de España. Lib. VI, Tít. VI, Ley XIV.

38 Novísima Recopilación de las leyes de España. Lib. VI, Tít. VI, Ley X, 24. 
Mediante decreto de 19 de noviembre de 1810, se hizo una recluta general en el contexto de la invasión napoleónica, muy potenciada por el fervor popular del momento. En esta ocasión se tiene que ampliar el arco de edad de los reclutas a ser quintados, admitiéndose a todos los hombres entre dieciséis y cuarenta y cinco años de edad y de cinco pies menos una pulgada de estatura mínima, en un principio, para formar el ejército en Andalucía ${ }^{39}$.

Llegado el Trienio Liberal, 1820-1823, los nuevos gobiernos renuevan el espíritu doceañista de equiparación de los ciudadanos: Está asimismo obligado todo español a defender la Patria con las armas, quando se llamado por la ley ${ }^{40}$. En estos momentos, los llamamientos a filas se realizan en nombre de las Leyes creadas por los Diputados: Don Fernando VII..., sabed: ... las Cortes usando de la facultad que se les concede por la Constitución han decretado... ${ }^{41}$, ya no se volverá a hacer en nombre del rey, como recordamos leer en las Instrucciones de de nuestros ejemplos de Expedientes de Quintas anteriores de 1742: Por quanto el Real Despacho de su Magestad (que Dios guarde ${ }^{42}$ ) y de 1762: Ha resuelto el Rey nuestro Señor (que Dios guarde) ${ }^{43}$.

Los expedientes de esta época incluyen también, como en casos anteriores, la "Comunicación Real" con el decreto de reclutamiento para el Ejército permanente, así como el cupo que le cabe a Torrelodones en unión de otros pueblos y su justificación; sigue llegando impreso por vereda, pero ahora proviene del "Gobierno Político de la Provincia", en nuestro caso de Guadalajara.

Actas, diligencias, autos, certificados expedidos por el secretario del Ayuntamiento, componen los documentos del expediente. A destacar la técnica documental practicada en la diligencia de Cumplimiento que inicia a renglón seguido del acuse recibo preceptivo, a modo de "reclamo" 44 que se sustancia en el folio siguiente.

Siguen los trámites y su reflejo documental con la "Publicación" el día siguiente y en acto continuo, tal como expresa, tiene lugar el "Alistamiento" de los mozos solteros y útiles de Torrelodones.

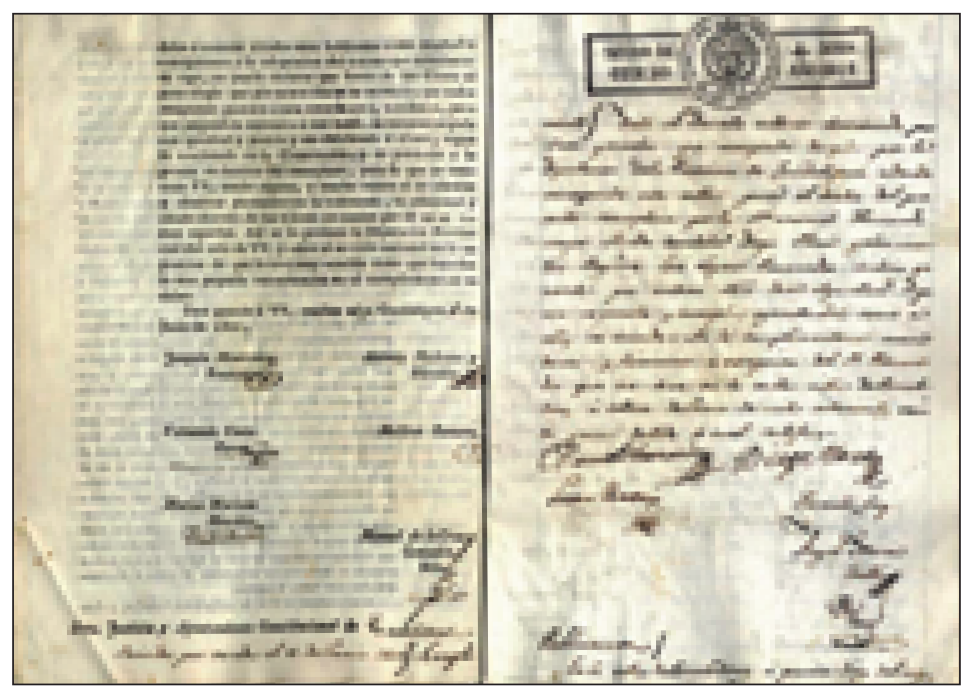

\footnotetext{
39 FEIJÓO GÓMEZ, Albino. Quintas y Protesta Social en el Siglo XIX, Madrid, 1996, p.36.

40 Constitución española de 1812 , Tít. $1^{\circ}$, Cap. $2^{\circ}$, art. 9.

41 AHMT. Torreldones Expedientes Generales de Reemplazo, C3,1,3r.

42 AMG. Expedientes Generales de Reemplazo, DH 57/2.1.

43 AMG. Expedientes Generales de Reemplazo, DH 57/5.2.

44 AHMT. Expedientes Generales de Reemplazo, C3-1, 6v-7r.
} 
El trámite del "Requerimiento", como cumplimiento del mandato de un auto anterior: fijese cédula en el parage acostumbrado en el día de mañana convocando a todos los mozos alistados y sus interesados para que el día veinte y ocho acudan a la Casa Consistorial a la rectificación del alistamiento ${ }^{45}$.

Se continúan los trámites con la "Comprobación y Rectificación del Alistamiento"; la solicitud a Madrid para que pase un cabo o sargento a ejecutar dicha medición [de los mozos] y se realiza el "Nombramiento del Defensor de los mozos". Por fin, se lleva a cabo el "Acto de la Medida", declarando que entre los trece llamados, dos están ausentes, uno enfermo, ocho defectuosos de talla y solamente dos llegan a la marca, por lo que se tiene que llevar a cabo un nuevo sorteo como solía ser frecuente.

Unos días después, el secretario certifica y traslada en acta el "Sorteo" de los dos quintos. El expediente se cierra con la "Entrega" y recepción de los soldados en la Caja particular a quintos de la provincia de Guadalajara firmado por el comandante de la plaza.

De 1834 tenemos otro ejemplo de Expediente para la celebración del sorteo de un soldado que ha correspondido a esta villa en el presente año para el reemplazo del egército de veinte y cinco mil hombres ${ }^{46}$.

En esta ocasión, en plena Guerra Carlista, será el Intendente provincial el que comunique en nombre del Supremo Consejo de la Guerra la orden de quintar que, como es costumbre, abre el expediente de manera que cada trámite reflejado en un documento esté estipulado en la instrucción de la Intendencia. Los referidos trámites se repiten en lo sustancial respecto a la década anterior, hallando como novedad los documentos de "Recado atento al cura y a otro testigo de providad", enviando al Secretario para que se lo notifique y el "Juicio de excepciones y acuerdo final". En anteriores llamamientos quedaba resuelto este acto de estudio de las excepciones y rectificación de alistamientos después de estudiar los informes médicos, las solicitudes de familiares y nuevas mediciones. En todo caso, siempre comienzan los expedientes con la notificación de la orden o instrucción y terminan con la entrega de los quintos ${ }^{47}$ en la Caja o Depósito del partido de Madrid, donde se hace cargo de ellos el comandante.

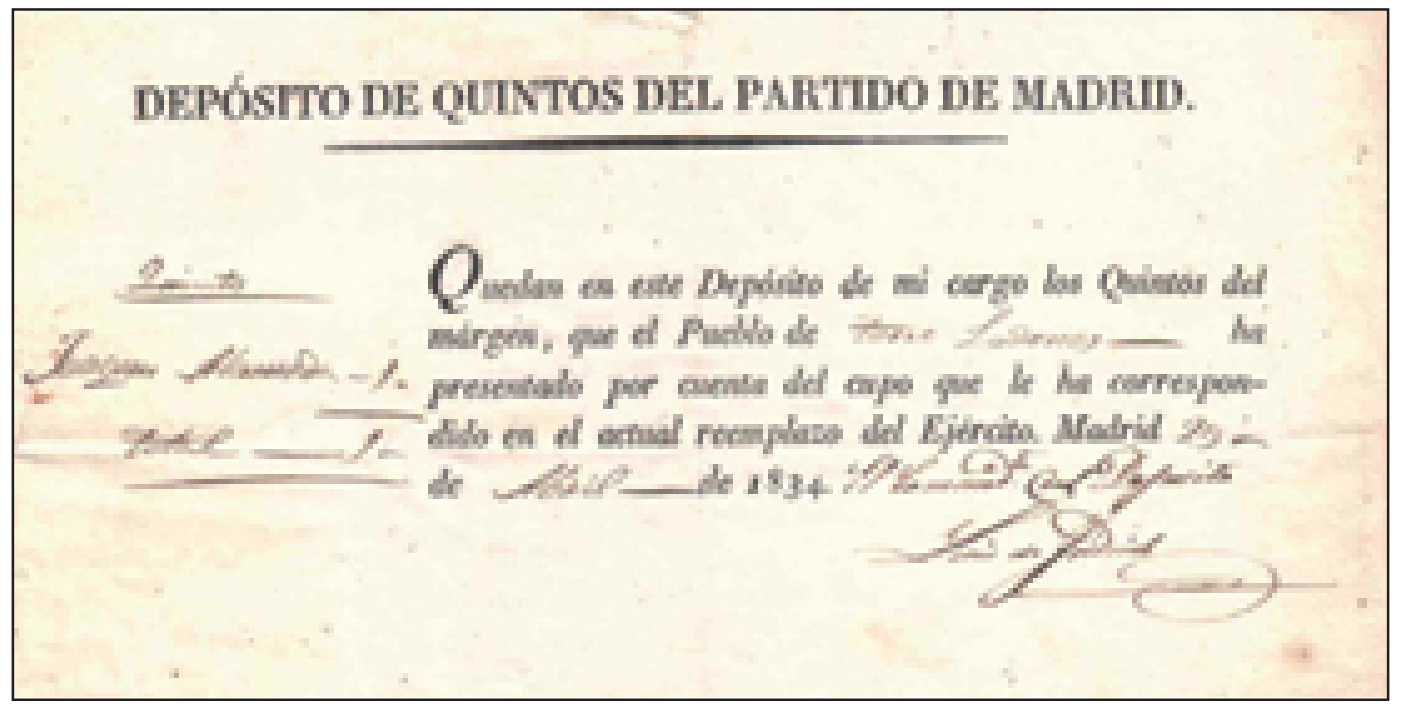

45 AHMT, Expedientes Generales de Reemplazo, C3, 1, 13r.

46 AHMT. Expedientes Generales de Reemplazo, C3-3.

47 AHMT_Expedientes Generales de Reemplazo, C3-3,22. 
En las Quintas de 1853 encontramos más novedades en el procedimiento. En primer término aparece el "Acuerdo" del Ayuntamiento para dar cumplimiento a la Ley de Reemplazos de 1850, seguido del "Padrón de almas" de la población, aunque siga estando presente en el proceso el cura con su propio padrón; el "Sorteo", que ahora se llama "General", la "Citación" personal a los mozos por medio del alguacil, cuando antes era suficiente con fijar en el sitio acostumbrado el edicto de obligada asistencia; el acta de "Declaración del soldado con su suplente"; el decreto del Ayuntamiento dando por buena la "Certificación del médico" y "Acuerdo del Ayuntamiento para hacer efectiva la entrega del soldado".

En 1862, en la formación del Espediente de Quinta para el reemplazo del Ejército, se remiten a la vigente ley de reemplazos de ese año. Para el "Alistamiento" ya no incorporan el padrón general de la población, sino que se listan solamente los mozos que cumplen las condiciones requeridas $^{48}$. Por otro lado, en este mismo año se dictan varias reales órdenes respecto a los soldados que se fugan emigrando al extranjero o ultramar.

En el Ayuntamiento Popular de 1869, ya en la Primera República, se vuelven a tener de principal referencia los libros parroquiales y, en un sólo y único acuerdo inicial se da cumplimiento a la vigente ley de reemplazos.

En 1871 el procedimiento de "Alistamiento y Sorteo para la Quinta”, en un sólo documento se incorpora el anuncio del "Cumplimiento" de la ley de reemplazos, el "Alistamiento" y la convocatoria para la "Rectificación", quedando el resto de los trámites como en anteriores reemplazos.

Más escueto será aún en 1873 que, sin la diligencia de Cumplimiento, trasladan el acta de "Alistamiento" con la referencia a la ley de Reemplazos de 17 de marzo que es preceptivo cumplir.

Por otro lado, en 1885 comenzamos a tener constancia de "Expedientes de pobreza" con sus certificados del alcalde, cura y testigos, que suplen a las declaraciones y solicitudes que se incorporaban antes en el propio expedientes de quintas correspondiente para exceptuar a los mozos en especiales circunstancias. Con anterioridad, la declaración de pobreza de un mozo se reducía al trámite correspondiente dentro del expediente general de reemplazo.

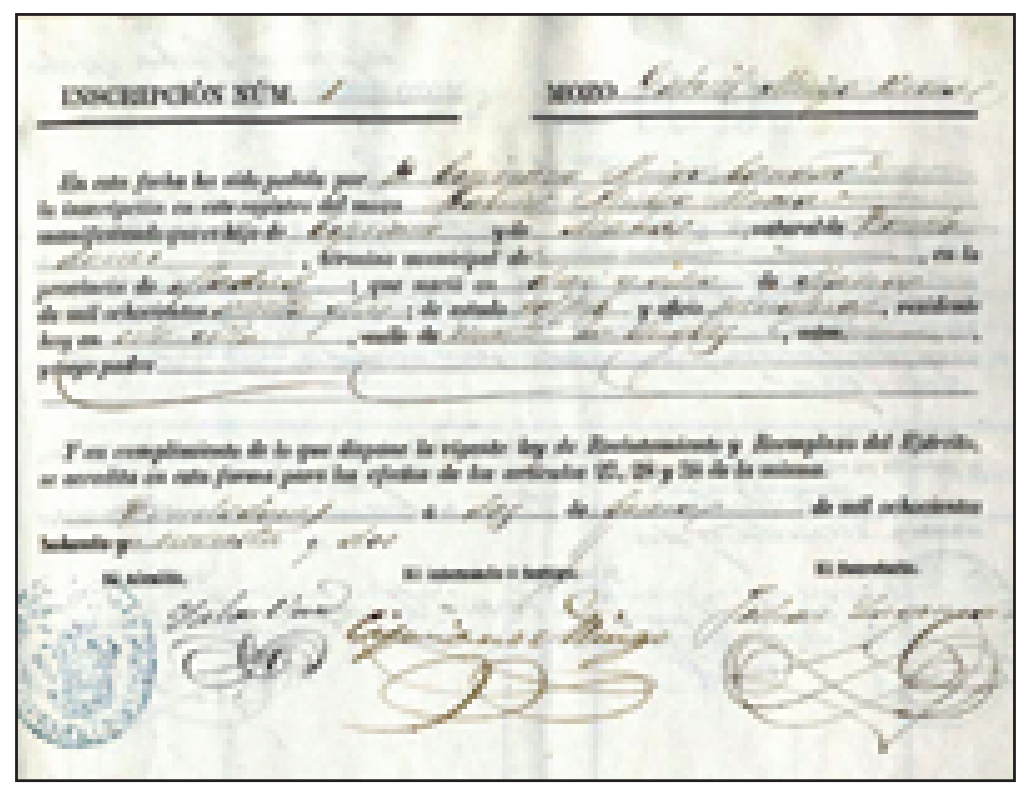

48 AHMT. Expedientes Generales de Reemplazo, C14-4,4r. 
Llegados a 1892 nos encontramos con Expedientes generales formados para el reemplazo del Ejército que cambian radicalmente desde su inicio. Será el padre o tutor del mozo el que solicita su ingreso, o así lo requiere el impreso a cumplimentar, como puede apreciarse en la imagen ${ }^{49}$.

El "Acta de Alistamiento" es un impreso a cumplimentar que hace constar la presencia de concejales, Alcalde, Cura y Juez Municipal, que dará lugar posteriormente a las rectificaciones oportunas, del "Reemplazo de 1892, también en impreso a cumplimentar, finalizando con el preceptivo recibo de "Entrega de Mozos a la Caja de la Zona Militar".

La mínima expresión procedimental tiene lugar en los documentos del expedientes del reemplazo de $1897^{50}$ con su carpetilla que lo preserva normalizado para todo el Estado que tiene tres únicos documentos: el primero de la sesión pública de "Clasificación, Declaración y Reclamaciones si las hubiera" y el segundo y tercero corresponde a los certificados del médico y del tallador para la medición de mozos.
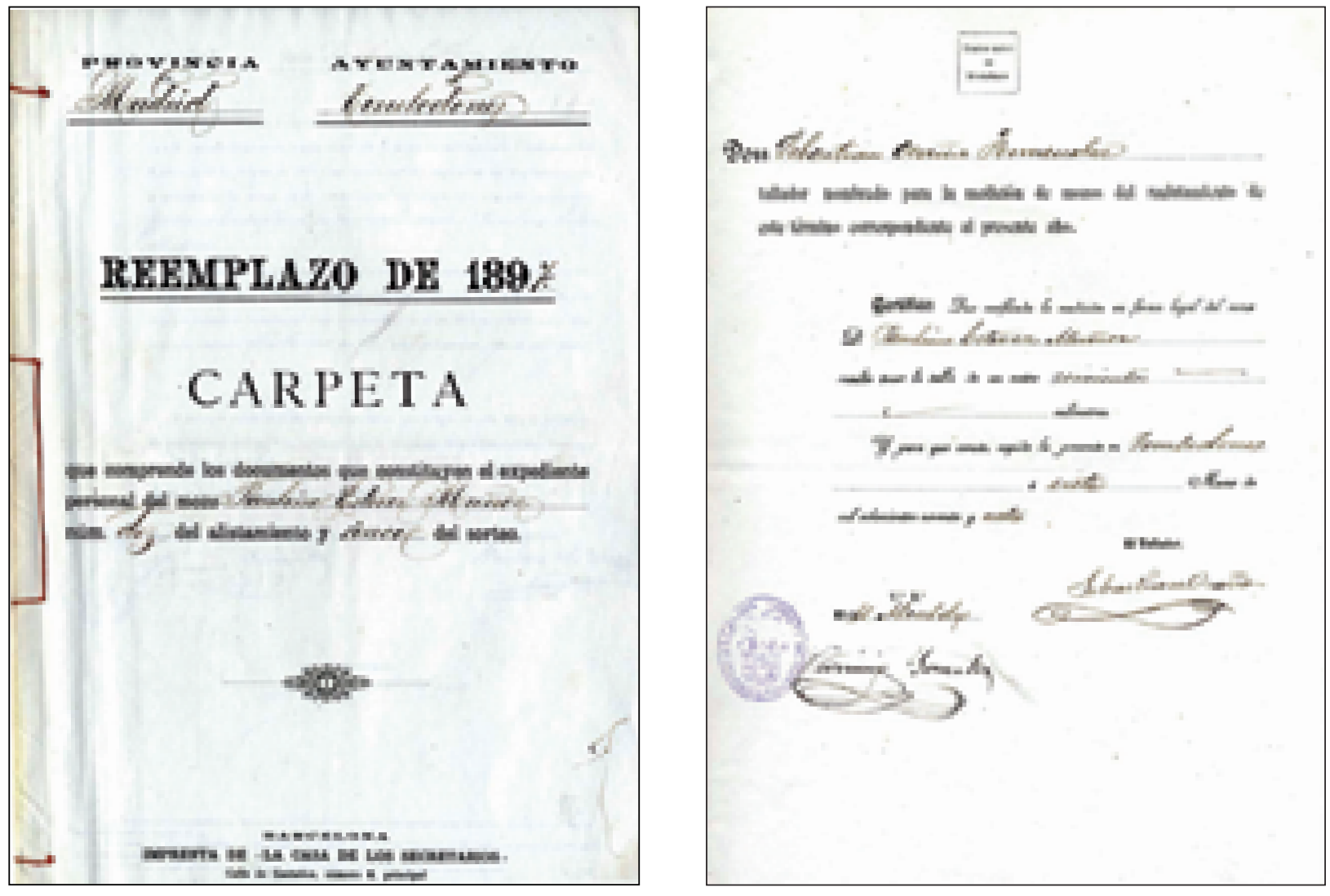

Los prófugos, como el caso de la declaración de pobreza de los mozos, tienen expedientes de procedimientos independientes con el certificado de no presentación y, si hubiere, declaraciones, nuevas citaciones y decretos. Interesante que aparezcan ya en la contraportadilla las Instrucciones para llenar los huecos que van numerados en este expediente.

49 AHMT_Expedientes Generales de Reemplazo_C6-3,2

50 AHMT_Expedientes Generales de Reemplazo_C6-3,13 


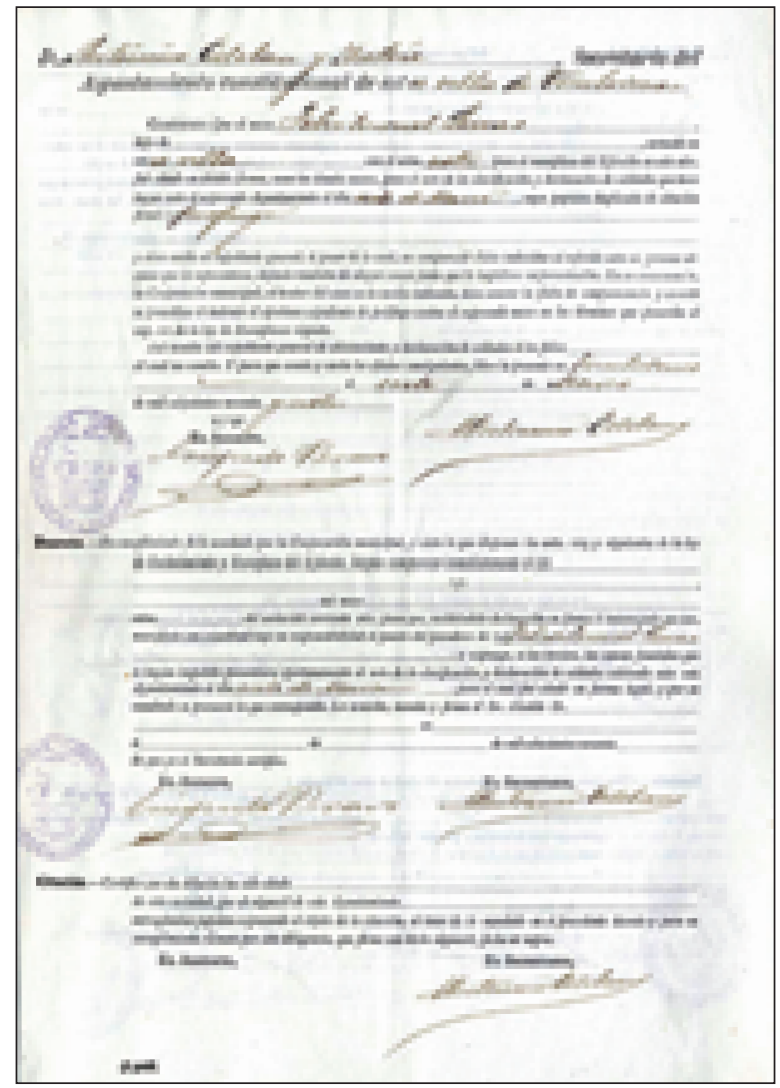

Acabando el siglo, en $1899^{51}$ es de resaltar que la técnica del sorteo sigue siendo la misma, es decir, la introducción de los nombres en bolas y éstas en globos, si bien, la mano inocente de un niño de corta edad se ha suplido por la del Alcalde para la extracción de las bolas del nombre y por un concejal para las de la suerte. En cuanto a los padrones de mozos, Para este sorteo se tendrán en cuenta, además de los libros parroquiales, los del Registro Civil.

Como se comprueba en el repaso cronológico realizado en estas dos centurias sobre la serie documental de Quintas, quedó muy atrás la forma inicial de llevar a cabo el procedimiento en asamblea abierta de todo el vecindario, convocado a toque de campana en el lugar que tienen por costumbre y cumpliendo de manera solemne un gran número de trámites. A partir de la segunda mitad del siglo XIX se tendería a simplificar el número de documentos independientes por cada trámite y, además, con unas estrictas normas estandarizadas, incluso del formato de los impresos.

\footnotetext{
51 AHMT_Expedientes Generales de Reemplazo_C6-15
} 